\title{
Effects of S-adenosyl-L-methionine on the invasion and migration of head and neck squamous cancer cells and analysis of the underlying mechanisms
}

\author{
LAURA MOSCA ${ }^{1}$, MICHELE MINOPOLI ${ }^{2}$, MARTINA PAGANO $^{1}$, FRANCESCA VITIELLO $^{1}$, \\ MARIA VINCENZA CARRIERO ${ }^{2}$, GIOVANNA CACCIAPUOTI ${ }^{1}$ and MARINA PORCELLI ${ }^{1}$ \\ ${ }^{1}$ Dipartimento di Medicina di Precisione, Università della Campania 'Luigi Vanvitelli', I-80138 Napoli; \\ ${ }^{2}$ Unità Progressione Neoplastica, Istituto Nazionale Tumori-IRCCS 'Fondazione G. Pascale', I-80131 Napoli, Italy
}

Received October 22, 2019; Accepted February 13, 2020

DOI: $10.3892 / \mathrm{ijo} .2020 .5011$

\begin{abstract}
S-Adenosyl-L-methionine (AdoMet) is the principal methyl donor in transmethylation reactions fundamental to sustaining epigenetic modifications. Over the past decade, AdoMet has been extensively investigated for its antiproliferative, pro-apoptotic and anti-metastatic roles in several types of human cancer. Head and neck squamous cell carcinoma (HNSCC) is the sixth most common type of cancer worldwide, and is an aggressive type of cancer that is associated with a high recurrence rate, metastasis and poor treatment outcomes. The present study demonstrates, for the first time, to the best of our knowledge, that AdoMet induces cell cycle arrest and inhibits the migratory and invasive ability of two different HNSCC cell lines, oral Cal-33 and laryngeal JHU-SCC-011 cells. In both cell lines, AdoMet attenuated cell cycle progression, decreased the protein level of several cyclins and downregulated the expression of p21 cell cycle inhibitor. Moreover, AdoMet was able to inhibit Cal-33 and JHU-SCC-011 cell migration in a dose-dependent manner after 24 and $48 \mathrm{~h}$, respectively, and also induced a significant reduction in the cell invasive ability, as demonstrated by Matrigel
\end{abstract}

Correspondence to: Professor Marina Porcelli, Dipartimento di Medicina di Precisione, Università della Campania 'Luigi Vanvitelli', Via L. De Crecchio 7, I-80138 Napoli, Italy

E-mail: marina.porcelli@unicampania.it

Abbreviations: AdoMet, S-adenosyl-L-methionine; HNSCC, head and neck squamous cell carcinoma; HNC, head and neck carcinoma; uPA, urokinase-type plasminogen activator; MMP, matrix metalloproteinase; RTCA, real-time cell analysis; SMAD2, small mothers against decapentaplegic-2; SMAD3, small mothers against decapentaplegic-3; cDDP, cisplatin; TBST, Tris-buffered saline with Tween-20; PI, propidium iodide; HRP, horseradish peroxidase; Annexin V-FITC, Annexin V-fluorescein isothiocyanate; TBS, Tris-buffered saline; FACS, fluorescence-activated cell sorting; SD, standard deviation; EMT, epithelial-mesenchymal transition

Key words: S-Adenosyl-L-methionine, human head and neck cancer cells, migration and invasion processes, cell cycle arrest, cisplatin, drug combination invasion assay monitored by the xCELLigence RTCA system. Western blot analysis of several migration and invasion markers confirmed the inhibitory effects exerted by AdoMet on these processes and highlighted AKT, $\beta$-catenin and small mothers against decapentaplegic (SMAD) as the main signaling pathways modulated by AdoMet. The present study also demonstrated that the combination of AdoMet and cisplatin synergistically inhibited HNSCC cell migration. Taken together, these findings demonstrate that the physiological compound, AdoMet, affects the motility and extracellular matrix invasive capability in HNSCC. Thus, AdoMet may prove to be a good candidate for future drug development against metastatic cancer.

\section{Introduction}

Head and neck squamous cell carcinoma (HNSCC) is an aggressive life-threatening disease that constitutes $90 \%$ of head and neck carcinoma (HNC). HNSCC represents $3.5 \%$ of all cancers, and is one of the most common type of cancer worldwide despite significant progress in both early diagnosis and therapy. HNC originates from the mucosal epithelia of the upper aerodigestive tract, including the tongue, lip, salivary glands, sinuses, oral cavity, pharynx, larynx and thyroid $(1,2)$. Over the past few years, although advanced therapies have been applied for the treatment of HNC, the 5-year survival rate has not increased significantly $(3,4)$. Thus, there is an urgent need for the identification of new molecules with antitumor activity and less therapeutic toxicity than the currently used drugs and which are, at the same time, effective against HNC. In this regard, the identification and development of naturally occurring compounds may greatly contribute to this request.

S-Adenosyl-L-methionine (AdoMet, also known as SAM) is a widely naturally-occurring sulfonium compound that plays a primary role in cellular metabolism, since it is involved in a variety of important biochemical processes being indeed, the link to three key metabolic pathways: transmethylation, polyamine synthesis and transsulfuration (5-7). Over the past few decades, a number of in vitro and in vivo studies have demonstrated the involvement of AdoMet in various cellular processes, including proliferation, differentiation, cell cycle regulation and apoptosis, demonstrating that the sulfonium 
compound exerts pleiotropic effects on signal transduction in a variety of cell types and that AdoMet is able to halt the progression of several human tumors (8-13).

The development of metastases is a multistep process that requires active and specifically localized extracellular proteolysis, as well as the activation of a series of physiological and biochemical processes that govern the migration from the primary tumor site, invasion through the basement membrane, the entry of metastatic cells into blood vessels and finally, localization to the second site (14). Despite significant progress regarding potential therapeutic targets aimed at improving survival, the median time to mortality for patients affected by metastatic HNSCC is approximately 4 months (15). Therefore, the development of novel strategies aimed at preventing the migration and extracellular invasion of HNSCC is urgently required.

There is emerging evidence to document the involvement of AdoMet in the regulation of genes responsible for cell invasion and metastasis (16-19) and several research groups have investigated in depth the epigenetic regulation induced by AdoMet on the methylation status of genes involved in invasion and metastases processes, including the urokinase-type plasminogen activator (uPA) and matrix metalloproteinases (MMPs) (16,19). It has been demonstrated that the treatment of highly invasive MDA-231 breast cancer cells and PC-3 prostate cancer cells with AdoMet, significantly inhibits uPA and MMP2 expression, resulting in the potent inhibition of tumor cell invasion in vitro and tumor growth and metastasis in vivo $(16,17)$. Furthermore, Chik et al demonstrated that AdoMet synergizes with the DNA methylation inhibitor, 5-aza-2-deoxycytidine, to suppress uPA expression, thereby blocking MDA-MB-231 cell invasiveness (18). Another study demonstrated that in the highly invasive SW-620 colorectal cancer cell line, treatment with the sulfonium compound induced the inhibition of MMP2, and a decrease in membrane type 1 matrix metalloproteinase mRNA levels together with the upregulation of the tissue inhibitor of MMP2 (19). It was recently demonstrated that in human LM-7 and MG-63 osteosarcoma cells, AdoMet treatment led to a dose-dependent decrease in the proliferation and invasiveness of the tumor cells by inhibiting the expression of genes involved in the formation of metastasis, angiogenesis and cellular invasion, including uPA, MMP2 and MMP9 (20). More recently, it was reported that AdoMet was able to enhance the anti-metastatic effect of gemcitabine in pancreatic cancer through the inhibition of the JAK2/STAT3 pathway (21). In addition, and in association with selenium compounds in human cervical cancer HeLa cells, AdoMet was shown to inhibit cell proliferation, migration and adhesion by affecting the ERK and AKT signaling pathways (22).

In light of these data, the present study investigated the effects of AdoMet on cell proliferation, migration and invasion in HNSCC, and also aimed to elucidate the underlying mechanisms. The findings of this study demonstrate that AdoMet potently inhibits the migration and invasion of two different types of HNSCC cells, oral Cal-33 and laryngeal JHU-SCC-011 cells through the modulation of the AKT, $\beta$-catenin and SMAD signaling pathways. Moreover, the synergistic effects of AdoMet and cisplatin on cell migration are reported via the evaluation of wound recovery.
Taken together these results highlight AdoMet as a potential candidate for the development of novel treatment strategies for patients with HNSCC.

\section{Materials and methods}

Reagents. AdoMet was obtained from New England BioLabs, Inc. and prepared as previously described (13). The Annexin V-fluorescein isothiocyanate (V-FITC) Apoptosis Detection kit was purchased from eBioscience; Thermo Fisher Scientific, Inc. Tissue culture dishes were purchased from Corning Inc. Monoclonal antibodies (mAbs) to p21 (\#2947S), p53 (\#2524S), $\beta$-actin (\#3700S), $\beta$-catenin (\#8480S), AKT (\#2966S), phospho-AKT(\#2965S), cyclinE1 (\#4129S), cyclin A2(\#4656S), cyclin D1 (\#2978S), phospho-cdc25C (\#4901S), vimentin (\#5741S), E-cadherin (\#14472S), phospho-SMAD3 (\#9520S), SMAD3 (\#9523S) and polyclonal antibodies (polyAbs) to cyclin B1 (\#4138S), SMAD2 (\#3102S), phospho-SMAD2 (\#3104S), MMP2 (\#4022S) were purchased from Cell Signaling Technology, Inc.; uPA (AB2335602, cat. no. 119) polyAb was obtained from American Diagnostica, Inc., while mAbs directed to N-cadherin (05-915) and MMP9 (AB6001) were purchased from Merck Millipore. PolyAb to cdc25c (sc-13138) was purchased from Santa Cruz Biotechnology, Inc. Goat anti-rabbit IgG Alexa Fluor647 was obtained from Abcam. Horseradish peroxidase (HRP)-conjugated goat anti-mouse (GtxMu-003-DHRPX) and HRP-conjugated goat anti-rabbit (GtxRb-003-DHRPX) secondary antibodies were obtained from ImmunoReagents Inc. All buffers and solutions were prepared with ultra-high quality water. All reagents were of the purest commercial grade.

Cells and cell culture. The HNC cell lines, Cal-33 (oral squamous cancer cell line) and JHU-SCC-011 (laryngeal squamous cell carcinoma line) were obtained from the American Type Culture Collection (ATCC). The cells were cultured at $37^{\circ} \mathrm{C}$ in a $5 \% \mathrm{CO}_{2}$ humidified atmosphere and grown in RPMI supplemented with $10 \%$ heat-inactivated FBS, $100 \mathrm{U} / \mathrm{ml}$ penicillin, $100 \mu \mathrm{g} / \mathrm{ml}$ streptomycin and $1 \%$ L-glutamine.

Flow cytometry for the analysis of apoptosis. Annexin V-FITC was used in conjunction with the vital dye propidium iodide $(P I)$ as previously described (13) to distinguish apoptotic (Annexin V-FITC-positive, PI-positive) from necrotic (Annexin V-FITC-negative, PI-positive) cells (23). The detection of viable cells, early apoptotic cells, late apoptotic cells and necrotic cells was performed using a BD Accuri ${ }^{\mathrm{TM}} \mathrm{C} 6$ flow cytometer (BD Biosciences). For each sample, 20,000 events were acquired. Analysis was carried out by triplicate determination on at least 3 separate experiments.

Preparation of cell lysates. Oral cancer cells Cal-33 and JHU-SCC-011 cells, grown at $37^{\circ} \mathrm{C}$ for 24 and $48 \mathrm{~h}$ with or without AdoMet treatment, were collected by centrifugation, washed twice with ice-cold PBS and the pellet was lysed using $100 \mu 1$ RIPA Buffer. Following incubation on ice for $30 \mathrm{~min}$, the samples were centrifuged at 18,000 x $\mathrm{g}$ in an Eppendorf microcentrifuge for $30 \mathrm{~min}$ a $4^{\circ} \mathrm{C}$ and the supernatant was recovered. The protein concentration was determined using 
the Bradford method (24) and compared with the BSA standard curve.

Western blot analysis. Equal amounts of cell proteins were separated by SDS-PAGE (separating gel, 10 or $12 \%$; stacking gel, $5 \%$ ) and electrotransferred onto nitrocellulose membranes by Trans blot turbo (Bio-Rad Laboratories, Inc.). The mass of protein loaded per lane was $10-50 \mu \mathrm{g}$. Membrane were washed in TBST (10 mM Tris, pH 8.0, $150 \mathrm{mM} \mathrm{NaCl}, 0.05 \%$ Tween-20), and blocked with TBST supplemented with 5\% non-fat dry milk. Thereafter, the membranes were incubated overnight with the different primary antibodies at $4^{\circ} \mathrm{C}$ in TBST and 5\% non-fat dry milk, washed and incubated for $1 \mathrm{~h}$ at room temperature with HRP-conjugated secondary antibodies. All primary antibodies were used at a dilution of 1:1,000, and all secondary antibodies were used at a 1:5,000 dilution. Blots were then developed using enhanced chemiluminescence detection reagents ECL (Cyanagen,) and exposed to X-ray film. All films were scanned using ImageJ software (National Institutes of Health).

Flow cytometric analysis of the cell cycle. The Cal-33 and JHU-SCC-011 cells were seeded in 6-well plates at a density of $75 \times 10^{3}$ cells/well and $30 \times 10^{3}$ cells/well, respectively. The following day, the cells were treated with $300 \mu \mathrm{M}$ AdoMet. The Cal-33 and JHU-SCC-011 cells were recovered with trypsin-EDTA after 24 and $48 \mathrm{~h}$, respectively, washed in PBS and stained in a PI solution $(50 \mu \mathrm{g} / \mathrm{ml} \mathrm{PI}, 0.1 \%$ sodium citrate, $25 \mu \mathrm{g} / \mathrm{ml}$ RNase A, $0.1 \%$ triton in PBS) for $1 \mathrm{~h}$ at $4^{\circ} \mathrm{C}$ in the dark. Flow cytometric analysis was performed using a BD Accuri ${ }^{\mathrm{TM}}$ C6 flow cytometer (BD Biosciences). To evaluate cell cycle progression, PI fluorescence was collected as FL3-A (linear scale) using ModFIT software (Verity Software House). For each sample at least 20,000 events were analyzed in at least 3 different experiments giving a standard deviation (SD) $<5 \%$.

Fluorescence microscopy. To visualize the polymerized F-actin, cells $\left(\sim 2 \times 10^{4} /\right.$ sample $)$ were seeded on glass coverslips and cultured in growth medium in the absence (control) or presence of $300 \mu \mathrm{M}$ AdoMet. After 24 and $48 \mathrm{~h}$, the slides were washed with PBS, fixed with $2.5 \%$ formaldehyde, permeabilized with $0.1 \%$ Triton $\mathrm{X}-100$ for $10 \mathrm{~min}$ at $4^{\circ} \mathrm{C}$, and incubated with $0.1 \mu \mathrm{g} / \mathrm{ml}$ rhodamine-conjugated phalloidin (Sigma-Aldrich; Merck KGaA) for $40 \mathrm{~min}$ at $23^{\circ} \mathrm{C}(25)$. Nuclear staining was performed with the $10 \mathrm{mM}$ 4-6-diamidino-2-phenylindole (DAPI) dye (\#228549, Abcam) for $5 \mathrm{~min}$ at $23^{\circ} \mathrm{C}$. Finally, coverslips were mounted using $20 \%$ (w/v) Mowiol, and visualized with an Axiovert $200 \mathrm{M}$ fluorescence inverted microscope connected to a video camera (Carl Zeiss AG).

Invasion kinetic of cells monitored in real-time. This assay was performed using E-16-well plates and the xCELLigence Real-Time Cell Analysis (RTCA) technology as previously described (26). This technology measures impedance changes caused by the gradual increase in electrode surface occupation by cells during the course of time and provides a Cell Index value which is proportional to the number of adherent cells. The bottom wells were coated with $20 \mu \mathrm{g} /$ well Matrigel diluted in serum-free medium. Matrigel was allowed to polymerize for $1 \mathrm{~h}$ at $37^{\circ} \mathrm{C}$ prior to seeding the cells $\left(1 \times 10^{4}\right.$ cells/well) suspended in serum-free medium (control) or growth medium. Cells that cross the Matrigel adhere to the bottom of plates causing impedance changes, which are proportional to the number of invading cells. Matrigel invasion was monitored in real-time for $24 \mathrm{~h}$ and impedance changes were recorded and expressed as a cell index value. Slopes represent the change rate of cell index generated in a 3 to 20 -h time frame. The experiments were performed 3 times in quadruplicate.

Migration process evaluated by scratch-wound assay. The Cal-33 and JHU-SCC-011 cells were seeded in the appropriate number in a 6-well culture plates until $100 \%$ confluence was reached in $24 \mathrm{~h}$ and treated with 200 and $300 \mu \mathrm{M}$ AdoMet for 24 and $48 \mathrm{~h}$, respectively or with $300 \mu \mathrm{M}$ AdoMet alone or in combination with 0.18 or $0.36 \mu \mathrm{M}$ cisplatin (cDDP) (Sigma-Aldrich; Merck KGaA). Following treatment, in a sterile environment, a $200 \mu \mathrm{l}$ pipette tip was used to manually press against the top of the tissue culture plate and a vertical wound down was rapidly created through the confluent cellular monolayer. Carefully, medium and cell debris were aspirated away, replaced with $2 \mathrm{ml}$ of serum-free RPMI and initial images of the wounds were captured using a microscope (Leica Microsystems $\mathrm{GmbH}$ ) corresponding to time zero (T0). Following $24 \mathrm{~h}$ (T1) of treatment, snapshot images were captured to examine for wound closure. The wound areas of the control and treated cells were quantified using ImageJ software $1.48 \mathrm{v}$.

Statistical analysis. The results are expressed as the means of at least 3 independent experiments performed in quadruplicate, unless otherwise indicated. Data are expressed as the means $\pm \mathrm{SD}$. The means were compared using analysis of variance (ANOVA) plus the Bonferroni correction. A P-value $<0.05$ was considered to indicate a statistically significant difference.

\section{Results}

Effects of AdoMet on the apoptosis of Cal-33 and $J H U$-SCC-011 cells. In a previous study by the authors, to the best of our knowledge, the mechanisms underlying the antitumor effect of AdoMet on HNSCC were reported for the first time, demonstrating that AdoMet was able to induce apoptosis, involving a caspase-dependent mechanism paralleled by an increased Bax/Bcl-2 ratio in Cal-33 and JHU-SCC-011 cells following 48 and $72 \mathrm{~h}$ of treatment, respectively (13).

In order to evaluate the effects of AdoMet prior to the induction of apoptotic cell-death, the Cal-33 and JHU-SCC-011 cells were treated with $300 \mu \mathrm{M}$ AdoMet, and the apoptotic process was evaluated after 24 and $48 \mathrm{~h}$, respectively, by fluorescence-activated cell sorting (FACS) analysis after double labeling with Annexin V-FITC and PI. In the absence of any treatment, very few apoptotic cells were found in both cell populations (Fig. 1, control).

The Cal-33 cells treated with $300 \mu \mathrm{M}$ AdoMet for $24 \mathrm{~h}$, exhibited an approximately $10 \%$ greater number of apoptotic cells compared to the control group (Fig. 1A), while the JHU-SCC-011 cells treated with $300 \mu \mathrm{M}$ AdoMet for $48 \mathrm{~h}$ exhibited an approximately $3 \%$ greater number of apoptotic 
A

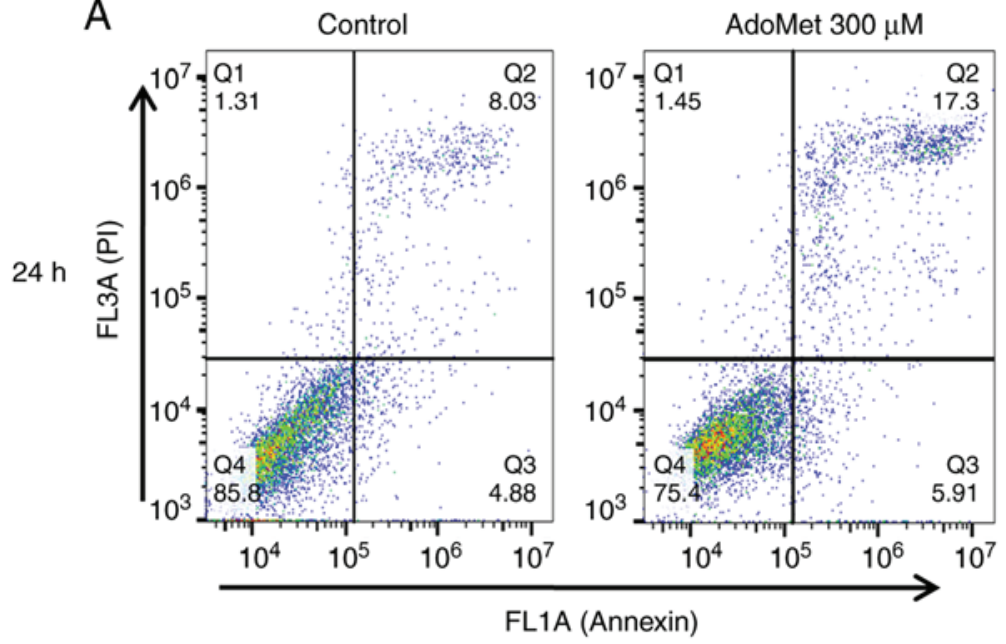

B

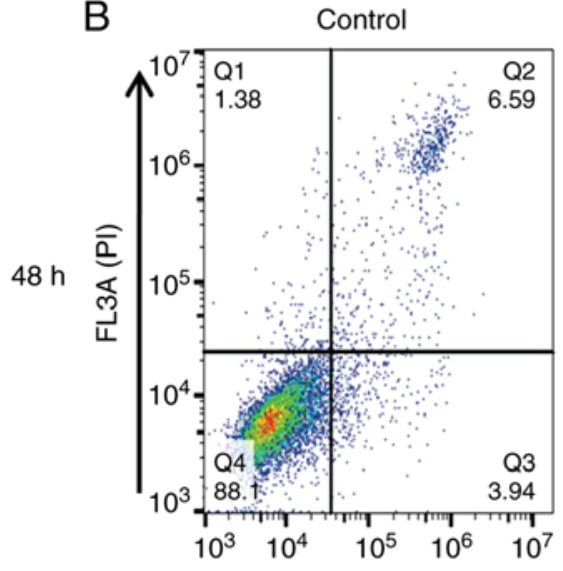

AdoMet $300 \mu \mathrm{M}$

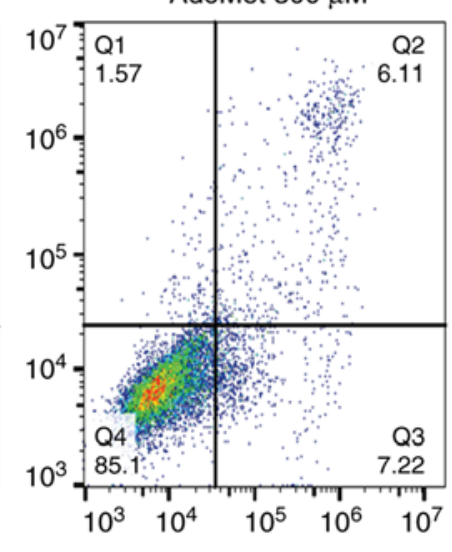

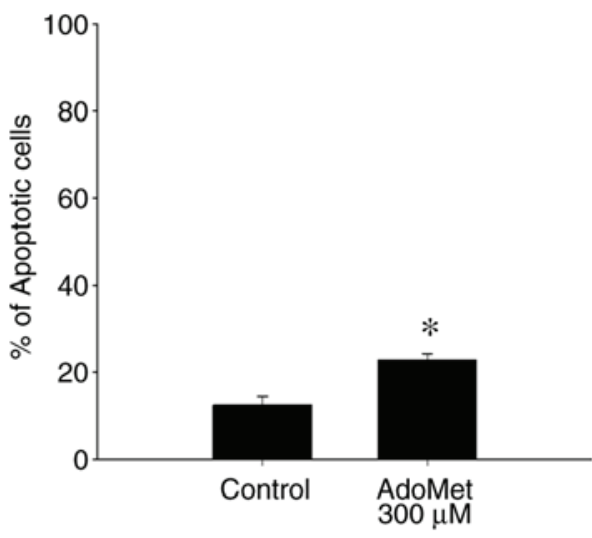

FL1A (Annexin)

Figure 1. Representative dot plots and histogram of both Annexin V-FITC and PI-stained HNSCC cells. (A) Cal-33 and (B) JHU-SCC-011 cells were treated or not (control) with $300 \mu \mathrm{M}$ AdoMet for 24 and $48 \mathrm{~h}$, respectively. Apoptosis was then evaluated by FACS analysis. In the different quadrants the percentages of cells are reported: viable cells, lower left quadrant (Q4); early apoptotic cells, bottom right quadrant (Q3); late apoptotic cells, top right quadrant (Q2); non-viable necrotic cells, upper left quadrant (Q1). For each sample $2 \times 10^{4}$ events were acquired. Analysis was carried out by triplicate determination of at least 3 separate experiments. Data are presented as means \pm SD. ${ }^{*} \mathrm{P}<0.05$ vs. control. HNSCC, head and neck squamous cell carcinoma; AdoMet, S-adenosyl-L-methionine.

cells compared to the control group (Fig. 1B). According to a previous study by the authors, the two cell lines are characterized by a different susceptibility to AdoMet. Therefore, the longer exposure time ( $48 \mathrm{~h}$ ) of the more resistant JHU-SCC-011 cells resulted in lower apoptotic rates compared with those observed following a shorter exposure time (24 h) of the more sensitive Cal-33 cells. These results indicated that AdoMet at a $300 \mu \mathrm{M}$ concentration and at $24 \mathrm{~h}$ for the Cal-33 and $48 \mathrm{~h}$ for the JHU-SCC-011 cells, did not induce any relevant apoptotic death in both cell lines.

AdoMet promotes the cell cycle arrest of Cal-33 and $J H U$-SCC-011 cells. In order to determine whether AdoMet treatment promotes cell cycle arrest, cell cycle progression was analyzed by flow cytometry in the Cal-33 and JHU-SCC-011 cells treated with $300 \mu \mathrm{M}$ AdoMet for 24 and $48 \mathrm{~h}$, respectively. As shown in Fig. 2A, AdoMet induced the marked accumulation of Cal-33 cells in the S/G2M phase with an increase from 47.6 to $61.9 \%$, while the percentage of cells in the G1 phase decreased from 50.2 to $33.9 \%$. A different effect was observed with the JHU-SCC-011 cells. Indeed, as shown in Fig. 2B, following AdoMet treatment, the G1 and G2/M phase populations decreased from 44.6 to $28.4 \%$ and from 14.7 to $7.6 \%$, respectively, with a concomitant significant increase from 36.1 to $61 \%$ of cells in the $\mathrm{S}$ phase. These results demonstrate that AdoMet is able to modulate cell cycle progression of HNSCC cells.

To further investigate the effects of AdoMet on cell cycle distribution, the expression level of several key cell cycle regulators, such as cyclin D1, E1, A2 and B1 was examined by western blot analysis. As shown in Fig. 2C and 2D, a dose-dependent decrease in the expression of cyclin B1, E1 and D1 was observed in the Cal-33 and JHU-SCC-011 cells, respectively following treatment with AdoMet compared to the untreated cells. The level of cyclin A2 was shown to decrease only with the $300 \mu \mathrm{M}$ concentration of AdoMet in the Cal-33 cells in (Fig. 2C), while a dose-dependent decrease was observed in the expression of cyclin A2 in the JHU-SCC-011 cells. These findings suggest that AdoMet attenuated cell proliferation via the downregulation of cyclin expression. Subsequently, the expression levels of cdc25C, phospho-cdc25C, p53 and the cyclin-dependent inhibitor, p21, were examined. The 
A

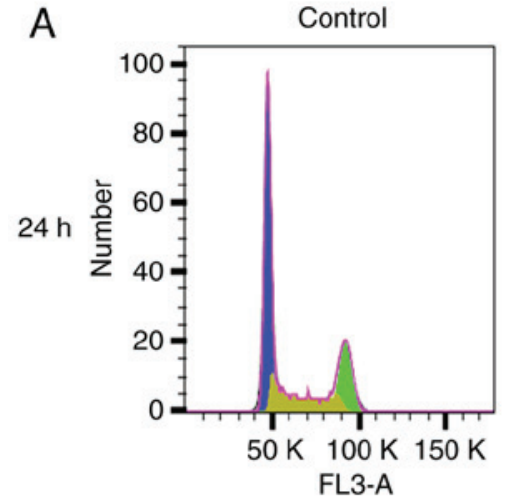

B

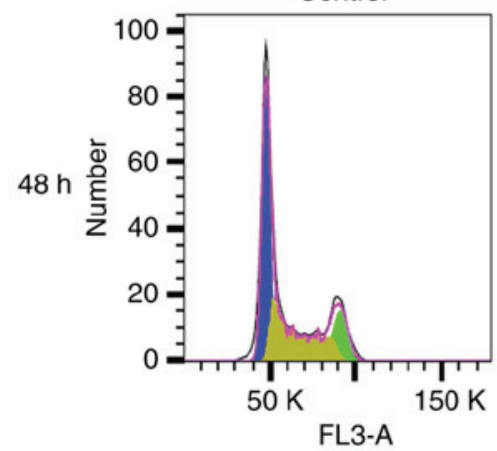

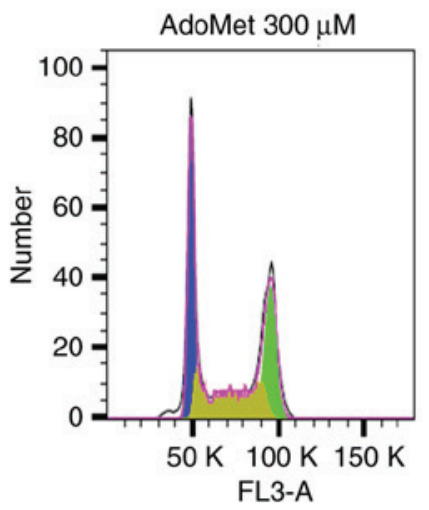

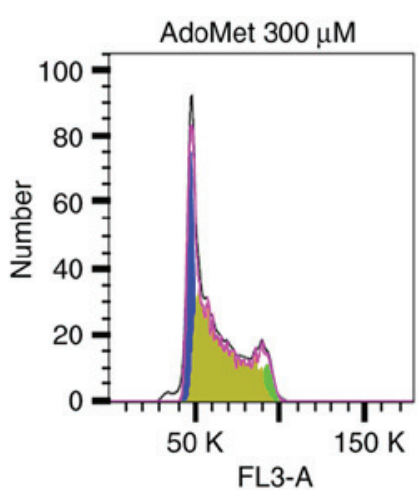

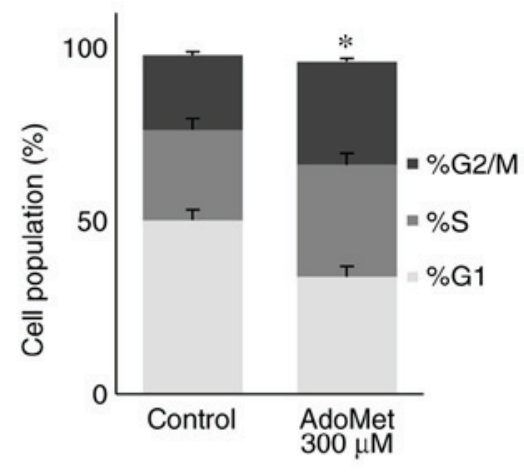

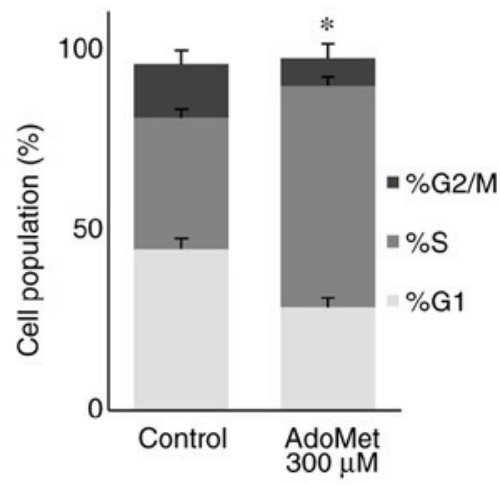

C

$24 \mathrm{~h}$
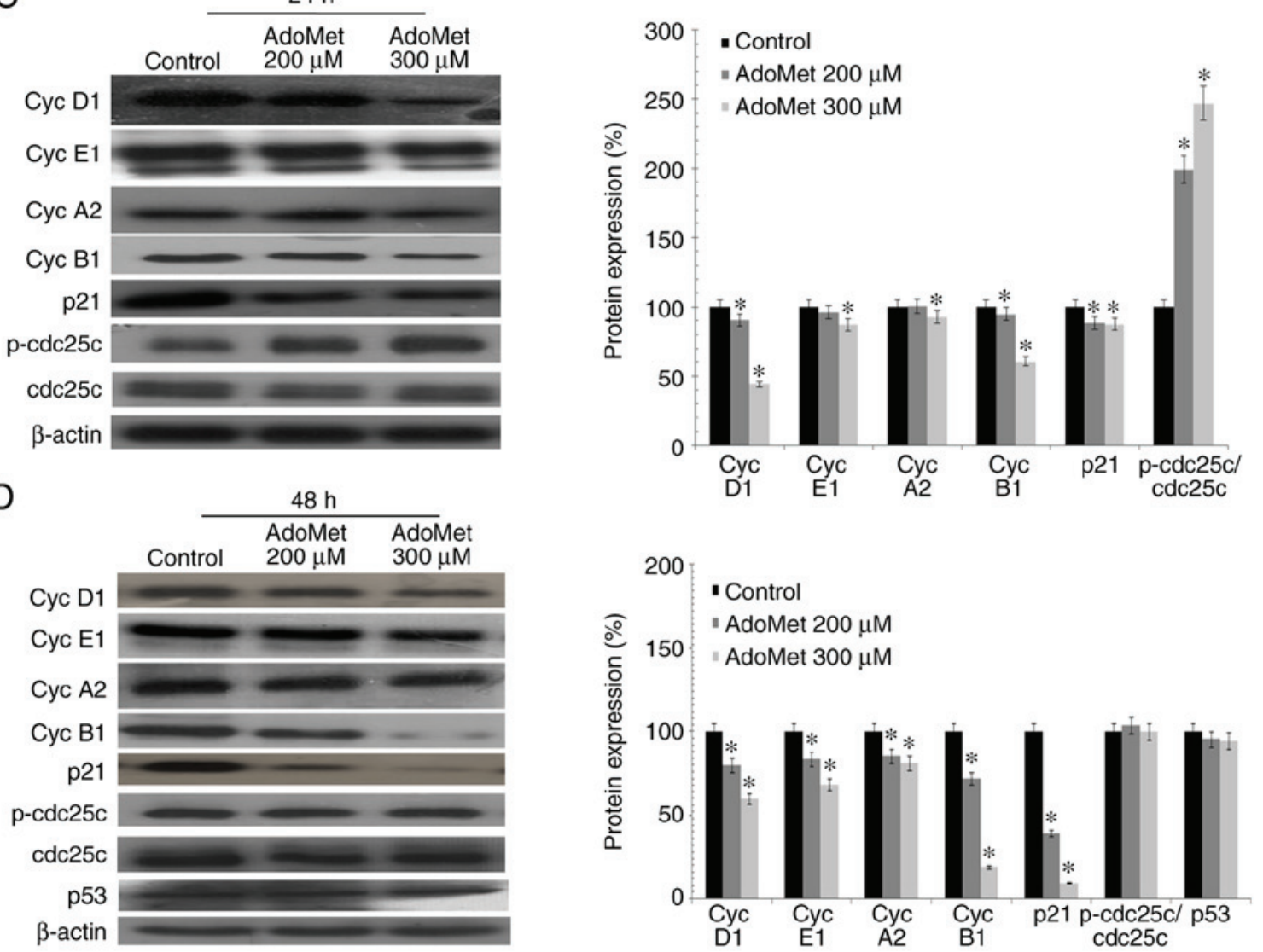

Figure 2. Effects of AdoMet on cell cycle of HNSCC cells. FACS analysis of Cal-33 and JHU-SCC-011 cells treated or not (control) with $300 \mu$ M AdoMet for 24 and 48 h, respectively. FACS analysis was then performed. Representative FACS histograms of PI-stained (A) Cal-33 and (B) JHU-SCC-011 cells. On the right bar diagrams are presented showing percentage of cells in each phase of the cell cycle. Data represent the average of 3 independent experiments. The means \pm SD are shown. For each sample at least $2 \times 10^{4}$ events were analyzed. The protein levels of cell cycle-regulatory proteins in (C) Cal-33 and (D) JHU-SCC-011 cells treated or not (control), with $200 \mu \mathrm{M}$ AdoMet or $300 \mu \mathrm{M}$ AdoMet for 24 and $48 \mathrm{~h}$ respectively, were measured by western blot analysis and the relative densitometric analyses are reported. Data, representative of 3 experiments performed with 3 different cellular preparations, are expressed as the means + standard deviation and are reported as a percentage of protein expression of the untreated control (100\%). $\mathrm{P}<0.05 \mathrm{vs}$. control. The housekeeping protein, $\beta$-actin, was used as a loading control. HNSCC, head and neck squamous cell carcinoma; AdoMet, S-adenosyl-L-methionine. 
A
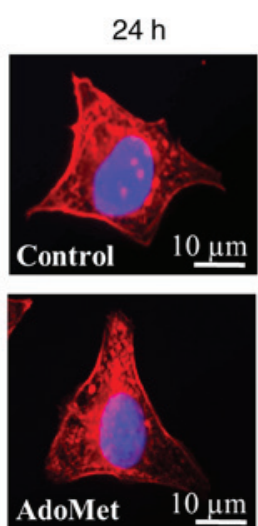

B

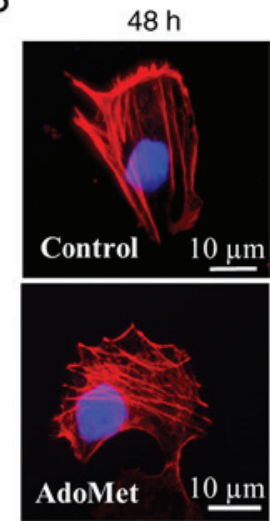

C

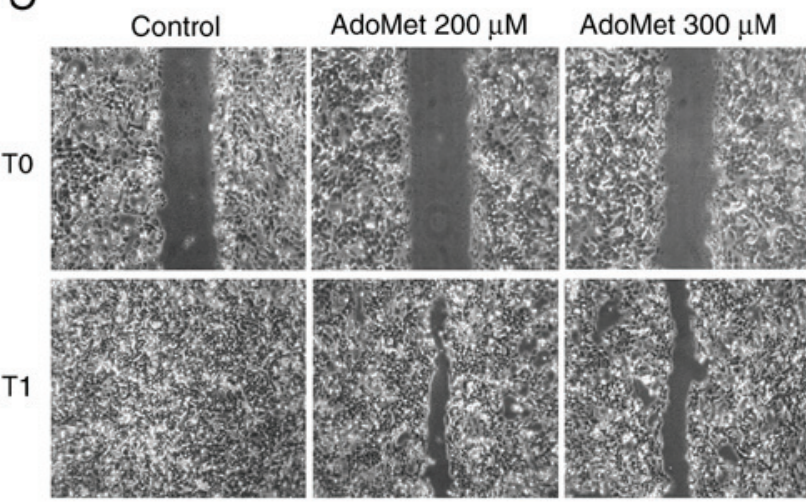

E

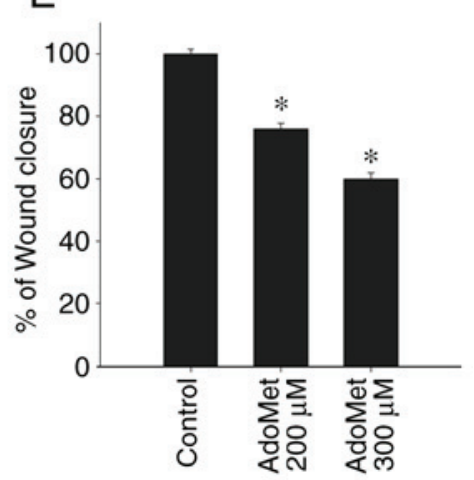

D

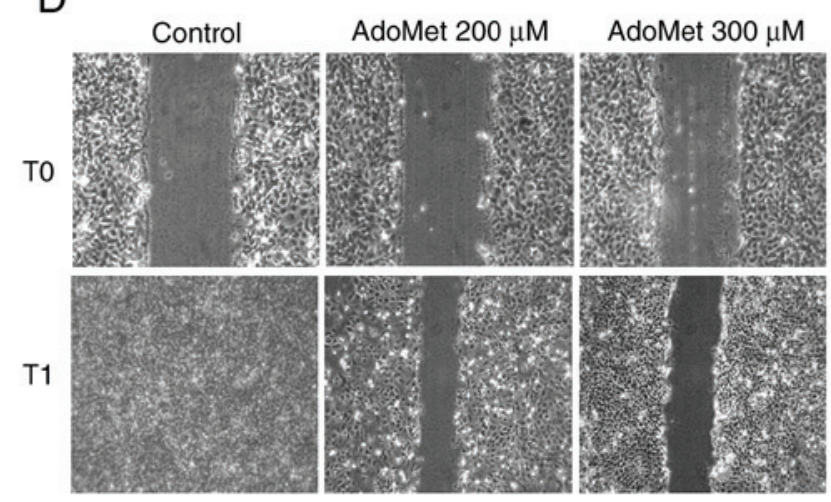

F

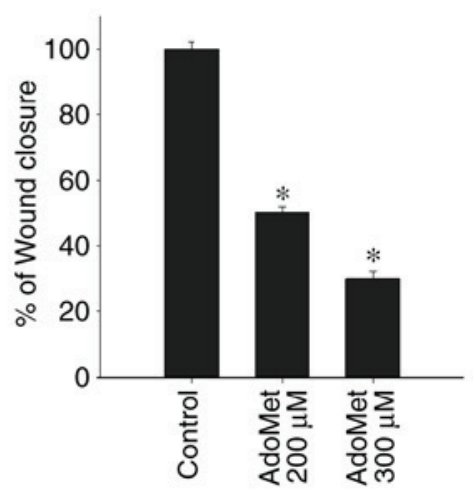

Figure 3. Effects of AdoMet on cytoskeletal organization and motility of HNSCC cells. (A) Cal-33 and (B) JHU-SCC-011 cells were pre-treated or not (control) with $300 \mu \mathrm{M}$ AdoMet for the indicated time periods and the F-actin polymerization was assessed by staining cells with rhodamine-conjugated phalloidin. Nuclei were stained blue with DAPI. Scale bar, $10 \mu \mathrm{m}$; original magnification, x1,000. Confluent monolayers of (C) Cal-33 and (D) JHU-SCC-011 cells exposed to diluents (control), or treated with 200 or $300 \mu \mathrm{M}$ AdoMet for 24 and $48 \mathrm{~h}$, respectively, were scratched with a micropipette tip and snapshot images were captured using a microscope to examine for wound closure. Images of the wounds corresponding to time zero (T0) and after $24 \mathrm{~h}$ (T1) of scraping in both cell lines are presented. Histograms (panel E and F) reporting the quantification of the wound area calculated as a percentage of the control using ImageJ software are depicted. Data represent the average of 3 independent experiments. The means \pm SD are shown. ${ }^{*} \mathrm{P}<0.05$ vs. control. HNSCC, head and neck squamous cell carcinoma; AdoMet, S-adenosyl-L-methionine.

results revealed a substantial dose-dependent increase in the phospho-cdc $25 \mathrm{C} / \mathrm{cdc} 25 \mathrm{C}$ ratio in the Cal-33 cells, while no significant change was detected in the JHU-SCC-011 cells. Notably, p21 expression was significantly decreased in both cell lines following AdoMet treatment, while the expression of p53, which is mutated in the Cal-33 cells, did not appear to be modified in the JHU-SCC-011 cells, indicating that the AdoMet-induced cell cycle arrest is a p53/p21-independent process.

Effects of AdoMet on the cytoskeletal organization and migration of Cal-33 and JHU-SCC-011 cells. In order to investigate the early intracellular effects occurring during AdoMet treatment, cytoskeletal organization and the motility of Cal-33 and JHU-SCC-011 cells exposed to $300 \mu \mathrm{M}$ AdoMet for 24 and $48 \mathrm{~h}$, respectively were analyzed. As revealed by the rhodamine-phalloidin staining of F-actin polymerization, in the absence of AdoMet, both the Cal-33 and JHU-SCC-011 cells exhibited a well-organized cytoskeleton with condensed aggregates localized below the membrane (Cal-33 cells) or stress fibers parallel to the longitudinal axis of the cells (JHU-SCC-011 cells). Cell exposure to AdoMet did not significantly modify the cytoskeletal organization of either the Cal-33 and JHU-SCC-011 cells (Fig. 3A and B). Conversely, AdoMet decreased the migration of the Cal-33 and JHU-SCC-011 cells in a wound healing experiment monitored for $24 \mathrm{~h}$. In both cases, the wounds disappeared after $24 \mathrm{~h}$ in the absence of AdoMet, as shown by the microscopy images of the same field recorded at time 0 and after $24 \mathrm{~h}$ (Fig. 3C and D). Cell exposure to 200 and $300 \mu \mathrm{M}$ AdoMet for $24 \mathrm{~h}$ led to an approximately 24 and $40 \%$ reduction, respectively, in the Cal-33 wound closure (Fig. 3C and E). Of note, the spreading of the JHU-SCC-011 cells was markedly reduced by AdoMet treatment for $48 \mathrm{~h}$. Indeed, treatment with 200 and $300 \mu \mathrm{M}$ AdoMet led to a 50 and $70 \%$ reduction in wound closure, respectively (Fig. 3D and $\mathrm{F}$ ). These findings thus indicate that AdoMet inhibits the migration of both HNSCC lines, without affecting cytoskeletal organization.

AdoMet affects the invasion of Cal-33 and JHU-SCC-011 cells on Matrigel. Since cell motility is a prerequisite for the acquisition of an invasive phenotype, the effects of AdoMet on the ability of Cal-33 and JHU-SCC-011 cells 

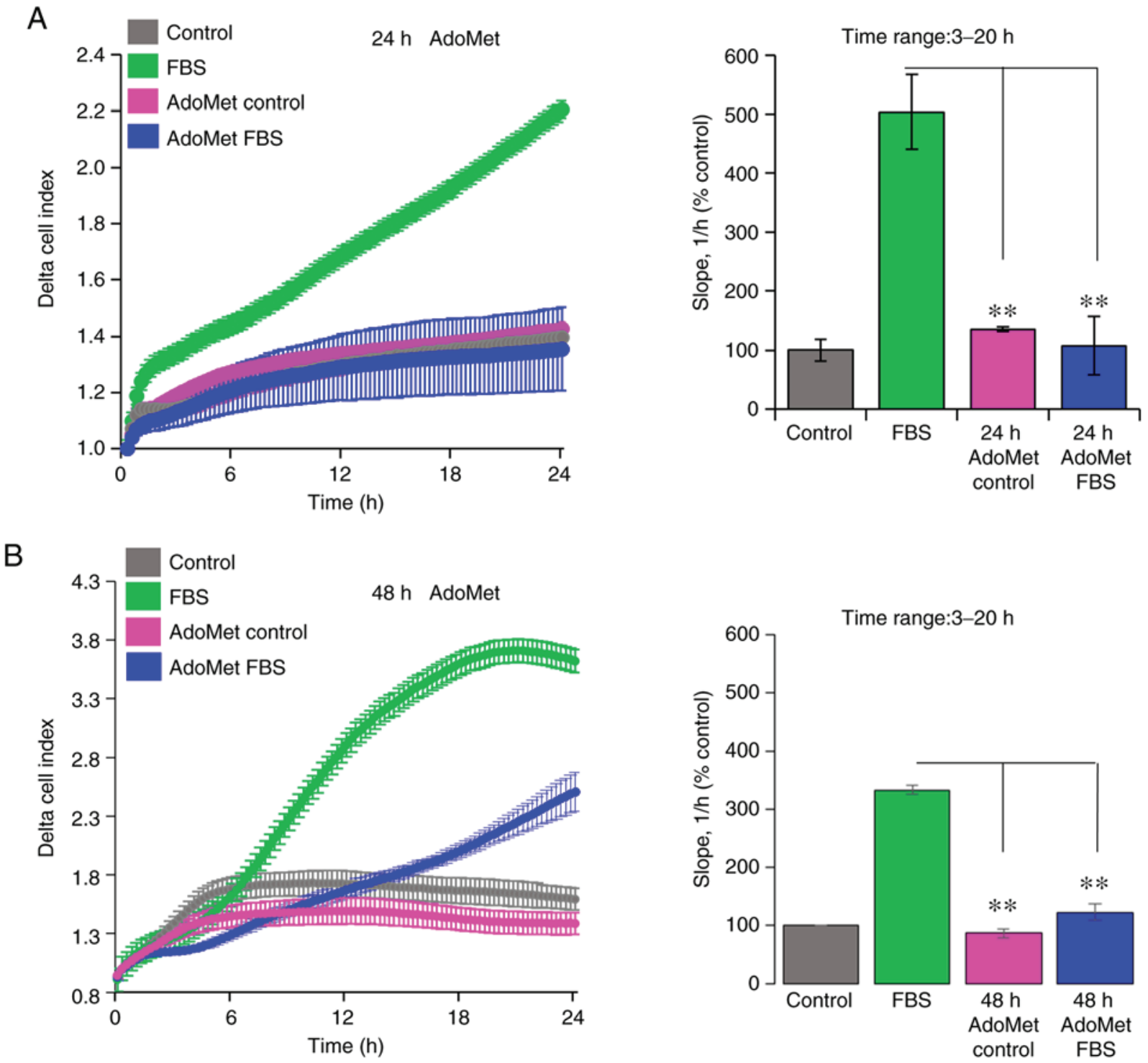

Figure 4. Effects of AdoMet on the invasion of HNSCC cells on Matrigel. Invasion of (A) Cal-33 and (B) JHU-SCC-011 cells on Matrigel treated for the indicated time periods with diluents (AdoMet control) or $300 \mu \mathrm{M}$ AdoMet, toward serum-free medium (control) or medium containing 10\% FBS as a source of chemoattractant. Matrigel invasion was monitored for $24 \mathrm{~h}$ as changes in the Delta Cell Index (calculated as function of the Cell Index at time $=0$ ) using the xCELLigence system. On the right, slopes representing the change rate of Cell Indexes generated in the 3 to 20-h timeframe are shown. Data represent the means \pm SD from 2 experiments performed in quadruplicate. ${ }^{* *} \mathrm{P}<0.0001$ vs. FBS. HNSCC, head and neck squamous cell carcinoma; AdoMet, S-adenosyl-L-methionine.

to cross the Matrigel, a reconstitute basal membrane using xCELLigence RTCA technology, were examined (26). The Cal-33 and JHU-SCC-011 cells treated with diluents or $300 \mu \mathrm{M}$ AdoMet for 24 and $48 \mathrm{~h}$, respectively, were seeded at the bottom of E-plates coated with polymerized Matrigel. Matrigel invasion was monitored in real-time for $24 \mathrm{~h}$ as the cell index changes due to the adhesion of invading cells to microelectrodes. Although to a different extent, both the Cal-33 (Fig. 4A) and JHU-SCC-011 (Fig. 4B) cells were able to cross the Matrigel, and AdoMet did not affect their basal cell invasion, as compared to the untreated cells (Fig. 4). According to the cell migration data, pre-exposure of the cells to $300 \mu \mathrm{M}$ AdoMet led to a 73 and $63 \%$ inhibition of Cal-33 and JHU-SCC-011 cell invasive ability, respectively, as indicated by the slopes representing the cell index changes generated in the 3 to 20 -h time frame (Fig. 4).
Taken together, these data highlight the inhibitory effect of AdoMet on the migratory and invasive ability of HNC cells, raising the possibility that AdoMet may be considered, not only as a pro-apoptotic drug for the treatment of HNSCC, but also as a good candidate for preventing the cell invasive ability.

AdoMet downregulates the levels of proteins involved in migration and in invasion processes. The metastatic process consists of a series of sequential, interrelated steps, including tumor cell detachment from the primary tumor, increased motility and invasion, proteolysis and resistance to apoptosis. To further examine the effects of AdoMet treatment on the motility and invasiveness of HNSCC cells, the main migration and invasion markers characterizing the epithelial-mesenchymal transition (EMT) process, such as E-cadherin and N-cadherin, belonging to a family of transmembrane glycoproteins that mediate cell-cell adhesions, and vimentin, a protein that 

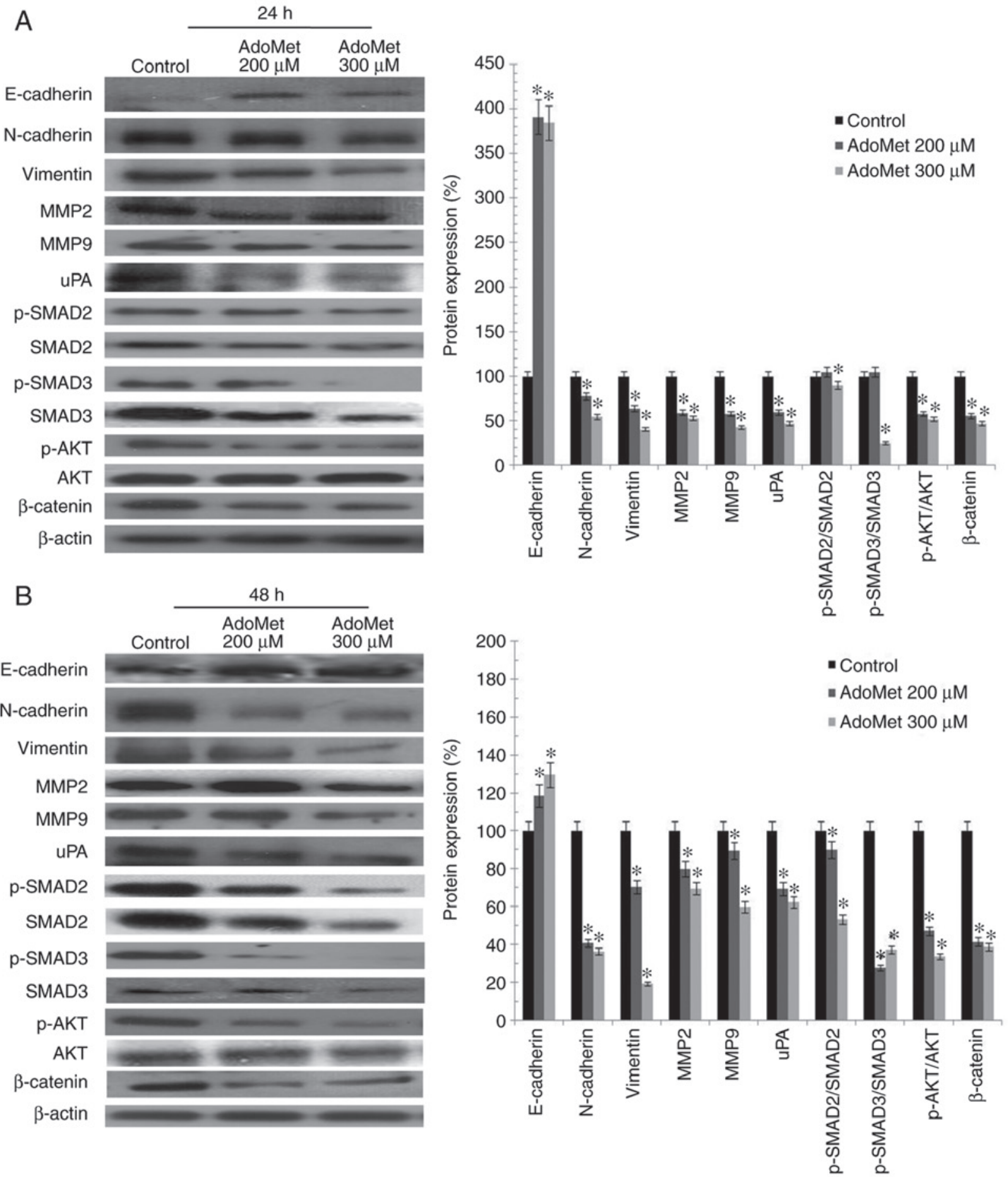

Figure 5. Effect of AdoMet on proteins involved in the migration and invasion processes and in the main cell growth and survival pathways of HNSCC. (A) Cal-33 and (B) JHU-SCC-011 cells were treated or not (control), with 200 or $300 \mu \mathrm{M}$ AdoMet for 24 and $48 \mathrm{~h}$, respectively. The expression levels of E-cadherin, N-cadherin, vimentin, MMP2, MMP9 and uPA along with phospho-AKT, AKT, $\beta$-catenin and p-SMAD2, SMAD2, p-SMAD3, SMAD3 were detected by western blot analysis using the total cell lysates. Densitometric analyses results are also presented. Data are representative of 3 experiments performed with 3 different cellular preparations, are expressed as the means + standard deviation and are reported as a percentage of the protein expression of the untreated control (100\%). "P<0.05 vs. control. For the equal loading of protein in the lanes, $\beta$-actin was used. HNSCC, head and neck squamous cell carcinoma; AdoMet, S-adenosyl-L-methionine; MMP, matrix metalloproteinase; uPA, urokinase-type plasminogen activator; SMAD, small mothers against decapentaplegic.

plays a significant role in anchoring organelles in the cytosol, were examined by western blot analysis (Fig. 5). The analysis revealed a marked concentration-dependent decrease in the $\mathrm{N}$-cadherin and vimentin levels, and a concomitant increase in E-cadherin levels in the Cal-33 and JHU-SCC-011 cells exposed to 200 and $300 \mu \mathrm{M}$ AdoMet for $24 \mathrm{~h}$, as compared with the control (untreated cells) (Fig. 5). In addition, according to the cell invasion data, treatment with 200 and $300 \mu \mathrm{M}$ AdoMet for $24 \mathrm{~h}$ led to a clear-cut reduction in the levels of the uPA, MMP2 and MMP9 proteolytic enzymes in both the Cal-33 and JHU-SCC-011 cell lysates (Fig. 5). Moreover, to further investigate the mechanisms underlying the inhibitory effects 
A
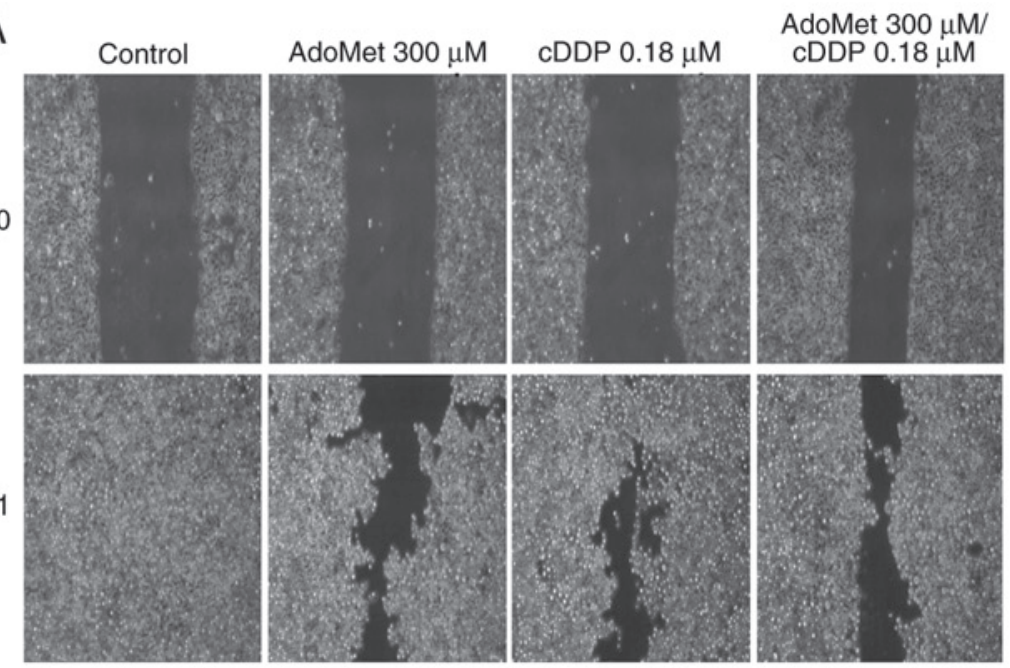

B
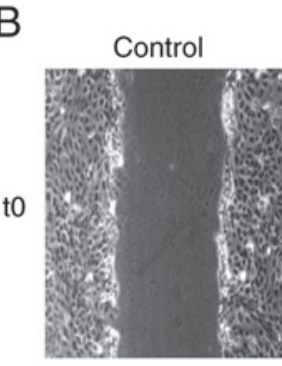

AdoMet $300 \mu \mathrm{M}$
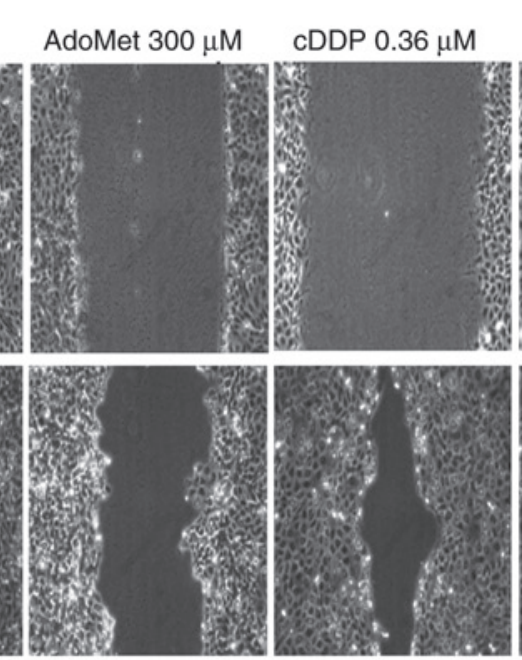

AdoMet $300 \mu \mathrm{M} /$ CDDP $0.36 \mu \mathrm{M}$
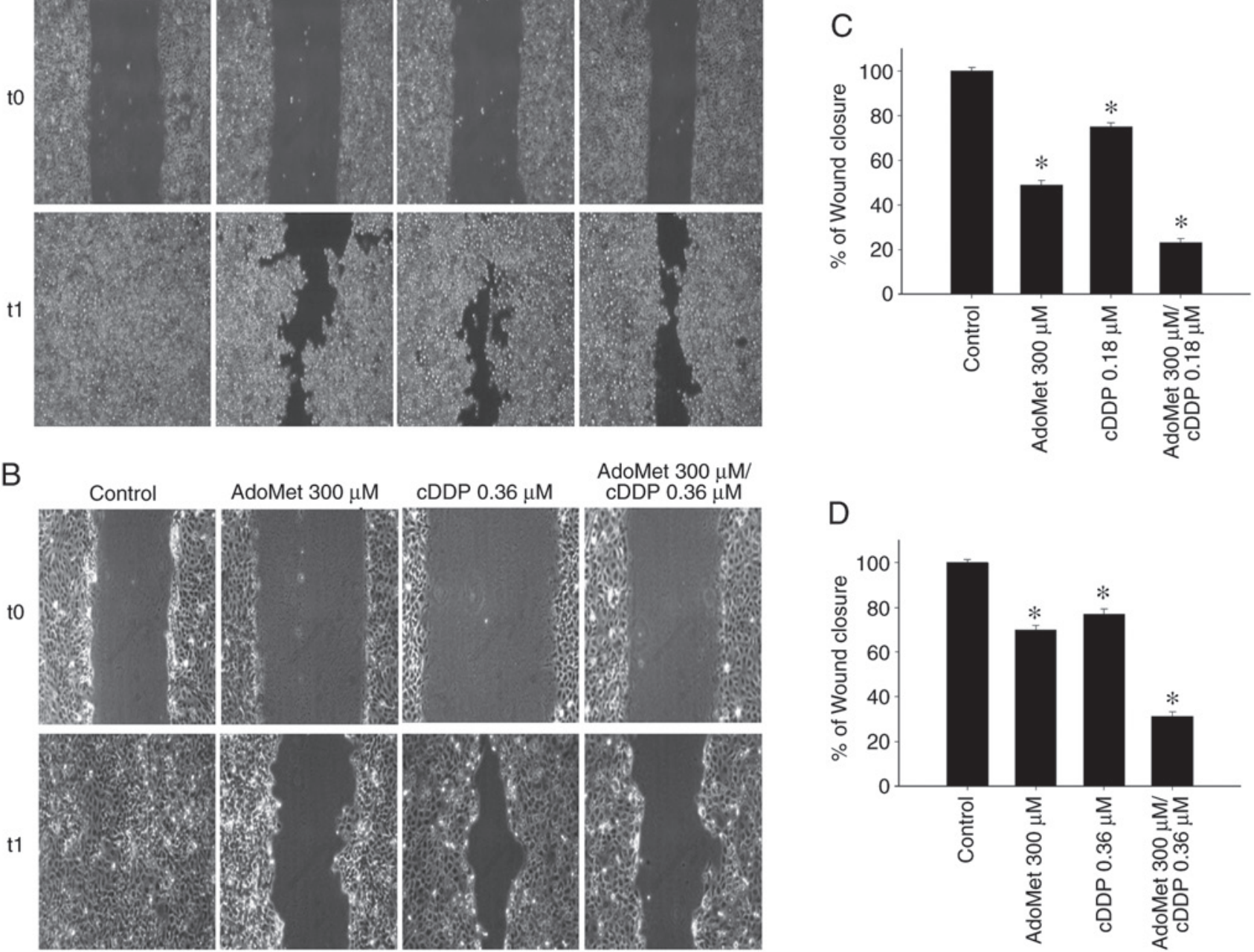

Figure 6. Effect of AdoMet/cDDP combination on cellular migration of HNSCC. The migratory ability of (A) Cal-33 and (B) JHU-SCC-011 cells was measured by wound healing assay. Confluent monolayers of Cal-33 and JHU-SCC-011 cells treated or not (control), with $300 \mu \mathrm{M}$ AdoMet with/without $0.18 \mu \mathrm{M}$ cDDP for $24 \mathrm{~h}$ or $0.36 \mu \mathrm{M} \mathrm{cDDP}$ for $48 \mathrm{~h}$, respectively, in comparison to treatment with cDDP alone were scratched with a micropipette tip and snapshot images were captured using microscope to examine for wound closure. Images of the wounds corresponding to time zero (T0) and after $24 \mathrm{~h}$ (T1) of scraping in both cell lines are presented. (C and D) Histograms reporting the quantification of the wound area calculated as a percentage of the control using ImageJ software are depicted. Data represent the average of 3 independent experiments. The means \pm SD are shown. $\mathrm{P}<0.05$ vs. control. HNSCC, head and neck squamous cell carcinoma; AdoMet, S-adenosyl-L-methionine; cDDP, cisplatin.

of AdoMet on the invasive and migratory ability of Cal-33 and JHU-SCC-011 cells, several cancer-related signaling pathways associated with invasion and migration were examined by western blot analysis. The results revealed that the sulfonium compound induced a decrease in the p-AKT/AKT, p-SMAD2/SMAD2 and p-SMAD3/SMAD3 ratios, and a downregulation in the expression of $\beta$-catenin (Fig. 5).

AdoMet synergistically enhances the cDDP-induced inhibition of cell migration. In a previous study by the authors, the synergistic effect of AdoMet in association with cDDP, an agent commonly used in cancer therapy, in inhibiting Cal-33 cell proliferation and in enhancing cell apoptosis, was demonstrated (13). It was found that the optimal combination of the two drugs, highly synergistic with the CalcuSyn calculation, corresponded to $200 \mu \mathrm{M}$ AdoMet and $0.18 \mu \mathrm{M}$ cDDP following $72 \mathrm{~h}$ of treatment. In the present study, in order to examine the synergistic effect induced by the AdoMet/cDDP combination on the migration process, the wound closures in the Cal-33 and JHU-SCC-011 cells treated with $300 \mu \mathrm{M}$ AdoMet plus/minus 0.18 or $0.36 \mu \mathrm{M}$ cDDP for 24 and $48 \mathrm{~h}$, respectively, were examined. As shown in Fig. 6, the wound width with the combination treatments were significantly greater compared to those of the control or to the single compound treatments with wound closure percentage values of 23 and $31 \%$ in the Cal-33 and JHU-SCC-011 cells, respectively compared to $100 \%$ of the control. The obtained results indicated that, when used in combination, AdoMet and cDPP were more effective in reducing cell migration than individual agents confirming that AdoMet potentiates the cytotoxic effects of cDDP on HNSCC.

\section{Discussion}

Although the majority of cancer-associated mortality cases are caused by metastatic cancer rather than primary tumors, this biology complex process remains the least understood 


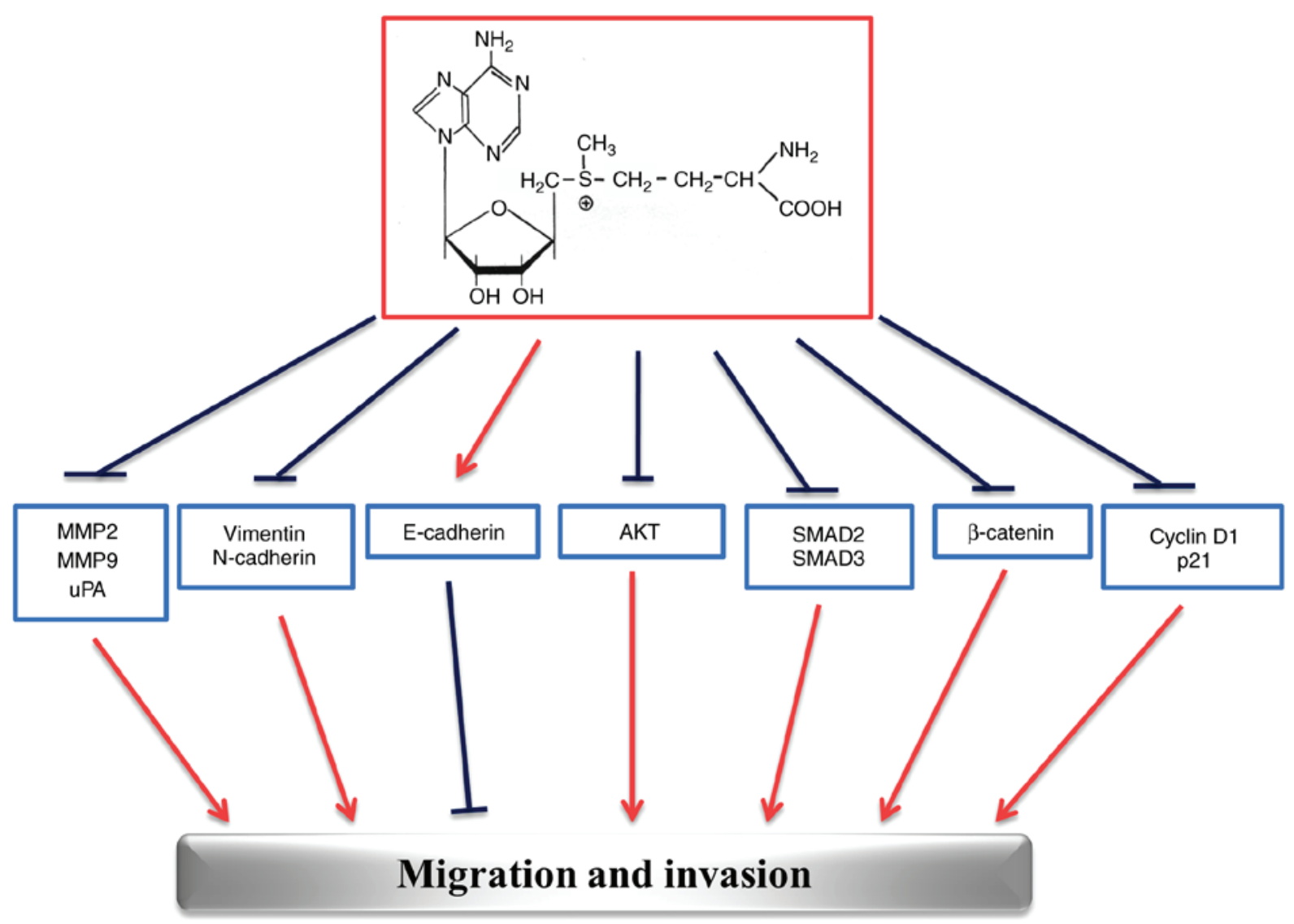

Figure 7. Schematic diagram summarizing the effects of AdoMet on the main markers of migration and invasion processes in HNSCC. HNSCC, head and neck squamous cell carcinoma; AdoMet, S-adenosyl-L-methionine; MMP, matrix metalloproteinase; uPA, urokinase-type plasminogen activator; SMAD, small mothers against decapentaplegic.

feature of cancer. The biochemical mechanisms and processes involved in metastatic cancer have been designed, such as potential targets for the prevention and inhibition of metastasis. HNSCC represents one of the most common types of tumor worldwide and almost $60 \%$ of patients with HNSCC develop metastases that limit their survival (1-4). Adverse toxic side-effects of chemotherapy during HNSCC treatment have shifted the focus towards anticancer natural compounds as a valuable source of novel and less toxic drugs that can be useful to block both tumor growth and metastatic spread of cancer cells.

The naturally occurring sulfur-containing nucleoside, AdoMet, is an important and ubiquitous biomolecule with a variety of biological functions, and the majority of these have been fully elucidated. AdoMet is one of the most frequently metabolites involved in intermediary metabolism, since it is the principal biological methyl donor in the cytosol of all mammalian cells. AdoMet also plays a role in other processes, such as transsulfuration reactions and polyamine synthesis (5-7).

Despite emerging data from the literature on the anti-proliferative and anti-metastatic effects exerted by AdoMet in a variety of cancer cells are accumulating (8-13), currently, only limited data are available on the molecular mechanisms underlying the anticancer effects of AdoMet on HNSCC (13), and the role of AdoMet in the invasion and migration of HNSCC has not been investigated to date, at least to the best of our knowledge.
Firstly, the present study evaluated the effect of AdoMet on cell viability. Cell cycle progression and its regulation is the key event of cell proliferation. In cancer cells, a number of cell cycle regulators, including p53, are mutated or inactivated, leading to uncontrolled cell proliferation. Thus, the ability of natural compounds with anticancer properties to reduce malignant growth by controlling cell cycle events, may be considered useful for cancer treatment and prevention.

In the current study, it was demonstrated that AdoMet induced a marked cell cycle arrest at the G2/M phase in Cal-33 cells, while it significantly increased the percentage of JHU-SCC-011 cells in the S phase. G2/M arrest is largely mediated through the phosphorylation of cdc25C, a p53-independent mechanism, and the consequential maintenance of cyclin-dependent kinases 1/cyclin B in the phosphorylated and inhibited state $(27,28)$. Of note, the present study found that AdoMet-induced G2/M phase arrest in Cal-33 cells was accompanied by a notable increase in the level of phosho-cdc25C protein. Moreover, it was found that AdoMet treatment modulated the cell cycle by downregulating the levels of cyclin D1, E1, A2, B1 and p21, while leaving the p53 levels unmodified, suggesting that cell cycle arrest at the G2/M and S phase in the Cal-33 and JHU-SCC-011 cells, respectively, is a p53/p21-independent process.

DNA methylation represents one of the most well-studied epigenetic processes in tumors (29). The ability of the sulfonium compound to regulate genes responsible for cell invasion and 
metastasis, has been well documented in human cancer and in particular, AdoMet has been reported to induce the downregulation of pro-metastatic genes, including uPA and MMPs $(16,19)$. Accordingly, the present study found that AdoMet treatment decreased the UPA, MMP2 and MMP9 content in the Cal-33 and JHU-SCC-011 cells. uPA is an extracellular serine protease implicated in tumor invasion and metastasis processes either directly by degrading extracellular matrix barriers or indirectly, by inducing plasmin-dependent activation of latent MMPs (30). Similar to uPA, MMPs are involved in extracellular matrix remodeling and degradation and play a role in modulating all stages of carcinogenesis, from tumor initiation to metastasis (31). The AdoMet-induced decrease in the levels of uPA, MMP2 and MMP9 are in good accordance with the reduced invasive ability on Matrigel of both the Cal-33 and JHU-SCC-011 cells treated with the sulfonium compound. It was found that AdoMet did not affect basal cell invasion, as compared to the untreated cells. However, despite different cell invasive abilities, both cell lines responded to AdoMet treatment to a similar extent, as $300 \mu \mathrm{M}$ AdoMet reduced the invasion of Cal-33 and JHU-SCC-011 cells on Matrigel by 73 and $63 \%$, respectively. Although the present study did not examine the effect of AdoMet on the invasive ability of HNSCC in animal models, to the best of our knowledge, this is first study to report the inhibitory effects of AdoMet on the invasive abilities of two HNSCC lines, Cal-33 and JHU-SCC-011 cells. The experimental evidence obtained by the in vitro experiments however, needs to be verified and broadened by further in vivo studies in the future.

The present study also demonstrated that AdoMet reduced the migration of both HNSCC cell lines. Notably, the inhibitory effect of AdoMet on cell migration could not be due to apoptosis for the following reasons: i) treatment of the Cal-33 and JHU-SCC-011 cells with $300 \mu \mathrm{M}$ AdoMet for 24 and $48 \mathrm{~h}$, respectively, did not trigger appreciable apoptotic cell death in both cell lines; ii) the cytoskeleton machinery, which is required for cell migratory ability, was not modified by AdoMet treatment. Moreover, in line with the AdoMet-dependent decrease in cell motility and invasiveness, it was found that AdoMet treatment led to an appreciable decrease in the levels of $\mathrm{N}$-cadherin and vimentin mesenchymal makers, and to a concomitant increase in the levels of the E-cadherin epithelial maker in HNSCC.

The characterization of the main growth and survival pathways involved in HNSCC seems to be the same in spite of the variety of risk factors and anatomical locations of origin. The molecular signaling pathways that appear to be most consistently modified are the PI3K/AKT and TGF $\beta /$ SMAD pathways (32). These pathways have been found to be responsible for neoplastic transformation, as well as for cancer invasion, a prerequisite for the development of metastatic disease. It has been reported that the phospho-AKT levels are positively with the prognosis of patients affected by oral squamous cell carcinoma, whereas the E-cadherin levels are inversely associated (33). In HNSCC, the activation of PI3K/AKT increases MMP9 expression, degrades E-cadherin and promotes cell invasion and migration (34). Moreover, the phosphorylation of AKT causes the inactivation of phosphorylated glycogen synthase kinase $3 b$, which is an important component of the canonical Wnt pathway, one of the hallmarks for the initiation of the EMT, leading to the accumulation of $\beta$-catenin in the nucleus and to the induction of cell proliferation and migration (35-37).

TGF- $\beta /$ SMAD signaling promotes EMT in late-stage cancer, playing an important role in the wound healing process, which requires cell migration $(38,39)$. Several studies have demonstrated synergistic effects between the TGF- $\beta /$ SMAD and $\mathrm{Wnt} / \beta$-catenin signaling pathways in a number of cellular functions, including wound healing (40-43). The activation of SMAD2/3, AKT and $\beta$-catenin leads to the upregulation of EMT-related transcription factors and mesenchymal markers, and to the downregulation of epithelial makers $(33,40-45)$. In line with this experimental evidence, the present study reported that AdoMet reduced the phospho-AKT levels, downregulated $\beta$-catenin accumulation and modulated the levels of SMAD2 and SMAD3, as well as the levels of their phosphorylated forms in the Cal-33 and JHU-SCC-011 cells, impairing cell proliferation and spreading.

It has been amply reported that cyclin D1, in addition to playing an important role in controlling the transition G1/S phase during cell cycle progression, is also a proto-oncogene involved in the regulation of cell migration and invasion (46). In analogy, p21, initially recognized as a downstream effector of p53-dependent cell cycle arrest induced by DNA damage, also functions as a 'two-faced' regulator. Indeed, depending on the cell type, cellular localization, the p53 status and the type and level of genotoxic stress, p21 can acquire either onco-suppressive or onco-promoting properties $(47,48)$. Cyclin D1 and p21 are often overexpressed in human cancers and their levels are associated with a high tumor grade, a poor prognosis and increased metastasis in several types of cancer (46-48). Furthermore, it has been recently demonstrated that p21 acts as a transcriptional co-regulator of SMAD that mediates TGF $\beta$-induced breast cancer cell migration and invasion (49). It has been also demonstrated that cyclin D1 cooperates with p21 to regulate TGF $\beta$-mediated breast cancer cell migration and that $21 /$ cyclin D1-depleted tumors displayed less invasive features (50). According to this experimental evidence, it is conceivable that the AdoMet-induced downregulation of p21 and cyclin D1 in the Cal-33 and JHU-SCC-011 cells, may represent a possible mechanism, which has not been reported to date, through which the sulfonium compound inhibits HNSCC migration through the TGF- $\beta /$ SMAD signaling pathway.

The multi-targeted effects exerted by AdoMet in HNSCC are summarized in Fig. 7. The ability of AdoMet to inhibit migration and invasion processes at multiple levels, stimulates great interest for future investigations and suggests that AdoMet may be an attractive candidate for the development of drugs against HNSCC.

Finally, to emphasize the potential role of AdoMet as an anticancer molecule, the present study analyzed the wound closure effectiveness of the combination of sulfonium compound with cDDP, a characteristic platinum complex already applied in HNSCC alone or in synergy with other drugs for therapeutic purposes (51). In a previous study on Cal-33 cells, it was demonstrated that after $72 \mathrm{~h}$, combined AdoMet/cDPP treatment resulted in a potent synergistic pro-apoptotic effect on Cal-33 cells; the use of AdoMet at the $200 \mathrm{mM}$ concentration meant that the concentration of active cDDP was able to be reduced up to $0.18 \mu \mathrm{M}$, the lowest concentration used in combination with other natural compounds (13). 
The present study demonstrates, for the first time, to the best of our knowledge, that AdoMet and cDPP synergize to prevent wound closure in Cal-33 and JHU-SCC-011 cells. Indeed, by a wound healing assay, it was found that, after $24 \mathrm{~h}$, the wounded areas in the combination treatment groups were significantly larger as compared to those of the control or single compound treatment groups.

The mechanism of action of cDDP has been linked to its ability to induce DNA damage via the formation of crosslinks with the purine bases on DNA, interfering with DNA repair mechanisms, and subsequently inducing the apoptosis of cancer cells. Moreover, multiple signal transduction pathways are activated by cDDP-induced genotoxic stress, through the activation of MAPK pathways, particularly JNK and ERK $(13,52)$. These mechanisms may contribute to either apoptosis or chemoresistance. Furthermore, it was recently demonstrated that cDDP has the ability to interfere with the proliferation, migration and invasion of nasopharyngeal carcinoma cells in vitro by suppressing the $\mathrm{Wnt} / \beta$-catenin/Endothelin- 1 axis via the activation of the $\mathrm{B}$ cell translocation gene 1 (52).

Taken together, these findings strongly support the notion that AdoMet may be considered as an anticancer agent in virtue of its ability to prevent the proliferation, migration and invasion of HNSCC cells. Furthermore, the fact that AdoMet effectively improves the cDDP-dependent inhibition of cell migration, provides the basis for including this physiological compound in the therapeutic management of metastatic HNSCC. Moreover, AdoMet has been available as a dietary supplement in the United States since 1999. Reviews of clinical studies to date have indicated that, at pharmacological doses, AdoMet has a low incidence of side-effects with an excellent record of tolerability. Moreover, no toxic or anti-proliferative effects have been reported in normal, non-tumorigenic cells (53-55). Thus, it is conceivable that the concentrations of AdoMet that would inhibit cancer cell proliferation, migration and invasion processes, utilized in the present, as well as in other studies, may be useful for further trials on patients.

\section{Acknowledgements}

Not applicable.

\section{Funding}

The present study was partially supported by Programme Valere 2019 (VANVITELLI per la Ricerca; Università della Campania 'Luigi Vanvitelli').

\section{Availability of data and materials}

All data generated or analyzed during this study are included in this published article or are available from the corresponding author on reasonable request.

\section{Authors' contributions}

MPo and LM conceived the study, designed the experiments, analyzed the data and drafted the manuscript. GC and MVC contributed to the design of the study and to the data analysis and reviewed the manuscript. MPa and FV performed the experiments, analyzed the data and prepared the figures; MM contributed to the design and accomplishment of the experiments based on Matrigel invasion and on cytoskeletal organization. All authors contributed to the revision of the manuscript and read and approved the final version of manuscript.

\section{Ethics approval and consent to participate}

Not applicable.

\section{Patient consent for publication}

Not applicable.

\section{Competing interests}

The authors declare that they have no competing interests.

\section{References}

1. Chin D, Boyle GM, Porceddu S, Theile DR, Parsons PG and Coman WB: Head and neck cancer: Past, present and future. Expert Rev Anticancer Ther 6: 1111-1118, 2006.

2. Marur S and Forastiere AA: Head and neck squamous cell carcinoma: Update on epidemiology, diagnosis, and treatment. Mayo Clin Proc 91: 386-396, 2016.

3. Kumar M, Nanavati R, Modi TG and Dobariya C: Oral cancer: Etiology and risk factors: A review. J Cancer Res Ther 12: 458-463, 2016.

4. Kulkarni P and Saxena U: Head and neck cancers, the neglected malignancies: Present and future treatment strategies. Expert Opin Ther Targets 18: 351-354, 2014

5. Lu SC: S-Adenosylmethionine. Int J Biochem Cell Biol 32: 391-395, 2000.

6. Mato MJ, Corrales FJ, Lu SC and Avila MA: S-Adenosylmethionine: A control switch that regulates liver function. FASEB J 16: 15-26, 2002.

7. Fontecave M, Atta M and Mulliez E: S-Adenosylmethionine: Nothing goes to waste. Trends Biochem Sci 29: 243-249, 2004.

8. Ansorena E, García-Trevijano ER, Martínez-Chantar ML, Huang ZZ, Chen L, Mato JM, Iraburu M, Lu SC and Avila MA: S-Adenosylmethionine and methylthioadenosine are anti-apoptotic in cultured rat hepatocytes but pro-apoptotic in human hepatoma cells. Hepatol 35: 274-280, 2002.

9. Lu SC and Mato JM: S-Adenosylmethionine in cell growth, apoptosis and liver cancer. J Gastroenterol Hepatol 23 (Suppl 1): S73-S77, 2008.

10. Martínez-López N, Varela-Rey M, Ariz U, Embade N, Vazquez-Chantada M, Fernandez-Ramos D, Gomez-Santos L, LuSC,MatoJMandMartinez-ChantarML:S-Adenosylmethionine and proliferation: New pathways, new targets. Biochem Soc Trans 36: 848-852, 2008.

11. Ilisso CP, Sapio L, Delle Cave D, Illiano M, Spina A, Cacciapuoti G, Naviglio S and Porcelli M: S-Adenosylmethionine affects ERK1/2 and Stat 3 pathways and induces apoptosis in osteosarcoma cells. J Cell Physiol 231: 428-435, 2016.

12. Cave DD, Desiderio V, Mosca L, Ilisso CP, Mele L, Caraglia M, Cacciapuoti G and Porcelli M: S-Adenosylmethionine-mediated apoptosis is potentiated by autophagy inhibition induced by chloroquine in human breast cancer cells. J Cell Physiol 233: 1370-1383, 2018.

13. Mosca L, Pagano M, Ilisso CP, Cave DD, Desiderio V, Mele L, Caraglia M, Cacciapuoti G and Porcelli M: AdoMet triggers apoptosis in head and neck squamous cancer by inducing ER stress and potentiates cell sensitivity to cisplatin. J Cell Physiol 234: 13277-13291, 2019.

14. Steeg PS: Tumour metastasis: Mechanistic insights and clinical challenges. Nat Med 12: 895-904, 2006.

15. Braakhuis BJ, Senft A, de Bree R, de Vries J, Ylstra B, Cloos J, Kuik DJ, Leemans CR and Brakenhoff RH: Expression profiling and prediction of distant metastases in head and neck squamous cell carcinoma. J Clin Pathol 59: 1254-1260, 2006. 
16. Pakneshan P, Szyf M, Farias-Eisner R and Rabbani SA: Reversal of the hypomethylation status of urokinase (uPA) promoter blocks breast cancer growth and metastasis. J Biol Chem 279: 31735-31744, 2004.

17. Shukeir N, Pakneshan P, Chen G, Szyf M and Rabbani SA: Alteration of the methylation status of tumor-promoting genes decreases prostate cancer cell invasiveness and tumorigenesis in vitro and in vivo. Cancer Res 66: 9202-9210, 2006.

18. Chik F, Machnes Z and Szyf M: Synergistic anti-breast cancer effect of a combined treatment with the methyl donor $\mathrm{S}$-adenosylmethionine and the DNA methylation inhibitor 5-aza-2'-deoxycytidine. Carcinogenesis 35: 138-144, 2014.

19. Hussain Z, Khan MI, Shahid M and Almajhdi FN: S-adenosylmethionine, a methyl donor, up regulates tissue inhibitor of metalloproteinase-2 in colorectal cancer. Genet Mol Res 12: 1106-1118, 2013.

20. Parashar S, Cheishvili D, Arakelian A, Hussain Z, Tanvir I, Khan HA, Szyf M and Rabbani SA: S-Adenosylmethionine blocks osteosarcoma cells proliferation and invasion in vitro and tumor metastasis in vivo: Therapeutic and diagnostic clinical applications. Cancer Med 4: 732-744, 2015.

21. Liu Y,BiT,LiuL,GaoQ,ShenGandQinL:S-Adenosylmethionine synergistically enhances the antitumor effect of gemcitabine against pancreatic cancer through JAK2/STAT3 pathway. Naunyn Schmiedebergs Arch Pharmacol 392: 615-622, 2019.

22. Sun L, Zhang J, Yang Q, Si Y, Liu Y, Wang Q, Han F and Huang Z: Synergistic Effects of SAM and selenium compounds on proliferation, migration and adhesion of HeLa cells. Anticancer Res 37: 4433-4441, 2017.

23. Vermes I, Haanen C, Steffens-Nakken $H$ and Reutelingsperger C: A novel assay for apoptosis. Flow cytometric detection of phosphatidylserine expression on early apoptotic cells using fluorescein labelled Annexin V. J Immunol Methods 184: 39-51, 1995.

24. Bradford MM: Rapid and sensitive method for the quantitation of microgram quantities of protein utilizing the principle of protein-dye binding. Anal Biochem 72: 248-254, 1976.

25. Fratangelo F, Camerlingo R, Carriero MV, Pirozzi G, Palmieri G, Gentilcore G, Ragone C, Minopoli M, Ascierto PA and Motti ML: Effect of ABT-888 on the apoptosis, motility and invasiveness of BRAFi-resistant melanoma cells. Int J Oncol 53: 1149-1159, 2018.

26. Ingangi V, Bifulco K, Yousif AM, Ragone C, Motti ML, Rea D, Minopoli M, Botti G, Scognamiglio G, Fazioli F, et al: The urokinase receptor-derived cyclic peptide [SRSRY] suppresses neovascularization and intravasation of osteosarcoma and chondrosarcoma cells. Oncotarget 7: 54474-54487, 2016.

27. Malumbres M and Barbacid M: Mammalian cyclin-dependent kinases. Trends Biochem Sci 30: 630-641, 2005.

28. Gutierrez GJ, Tsuji T, Cross JV, Davis RJ, Templeton DJ, Jiang W and Ronai ZA: JNK-mediated phosphorylation of Cdc25C regulates cell cycle entry and $\mathrm{G}(2) / \mathrm{M}$ DNA damage checkpoint J Biol Chem 285: 14217-14228, 2010.

29. Kanwal R and Gupta S: Epigenetic modifications in cancer. Clin Genet 81: 303-311, 2012.

30. Carriero MV and Stoppelli MP: The urokinase-type plasminogen activator and the generation of inhibitors of urokinase activity and signaling. Curr Pharm Des 17: 1944-1961, 2011.

31. Kessenbrock K, Plaks V and Werb Z: Matrix metalloproteinases: Regulators of the tumor microenvironment. Cell 141: 52-67, 2010

32. Kidacki M, Lehman HL, Warrick JI and Stairs DB: Signaling pathways supporting tumor invasion in head and neck squamous cell carcinoma. J Clin Exp Pathol 5: 227, 2014.

33. Silva BS, Yamamoto FP, Pontes FS, Cury SE, Fonseca FP, Pontes HA and Pinto-Júnior DD: TWIST and p-Akt immune expression in normal oral epithelium, oral dysplasia and in oral squamous cell carcinoma. Med Oral Patol Oral Cir Bucal 17: e29-e34, 2012

34. Zuo JH, Zhu W, Li MY, Li XH, Yi H, Zeng GQ, Wan XX, He QY, $\mathrm{Li} \mathrm{JH}, \mathrm{Qu} \mathrm{JQ}$, et al: Activation of EGFR promotes squamous carcinoma SCC10A cell migration and invasion via inducing EMT-like phenotype change and MMP-9-mediated degradation of E-cadherin. J Cell Biochem 112: 2508-2517, 2011.

35. Sheng S, Qiao M and Pardee AB: Metastasis and AKT activation. J Cell Physiol 218: 451-454, 2009.

36. Marcucci F, Stassi G and De Maria R: Epithelial-mesenchymal transition: A new target in anticancer drug discovery. Nat Rev Drug Discov 15: 311-325, 2016.
37. Xu W, Yang $\mathrm{Z}$ and Lu N: A new role for the PI3K/Akt signaling pathway in the epithelial-mesenchymal transition. Cell Adh Migr 9: 317-324, 2015.

38. Feng XH and Derynck R: Specificity and versatility in TGF- $\beta$ signaling through Smads. Annu Rev Cell Dev Biol 21: 659-693, 2005.

39. Suriyamurthy S, Baker D, Ten Dijke P and Iyengar PV: Epigenetic reprogramming of TGF- $\beta$ signaling in breast cancer. Cancers (Basel) 11: E726, 2019.

40. Guo W, Flanagan J, Jasuja R, Kirkland J, Jiang L and Bhasin S: The effects of myostatin on adipogenic differentiation of human bone marrow-derived mesenchymal stem cells are mediated through cross-communication between Smad3 and Wnt/beta-catenin signaling pathway. J Biol Chem 283: 9136-9145, 2008.

41. Minoo P and Li C: Cross-talk between transforming growth factor-beta and Wingless/Int pathways in lung development and disease. Int J Biochem Cell Biol 42: 809-812, 2010.

42. Liu J, Wang Y, Pan Q, Su Y, Zhang Z, Han J, Zhu X, Tang C and Hu D: Wnt/ß-catenin pathway forms a negative feedback loop during TGF- $\beta 1$ induced human normal skin fibroblast-to-myofibroblast transition. J Dermatol Sci 65: 38-49, 2012

43. Boldbaatar A, Lee S, Han S, Jeong AL, Ka HI, Buyanravjikh S, Lee JH, Lim JS, Lee MS and Yang Y: Eupatolide inhibits the TGF- $\beta 1$-induced migration of breast cancer cells via downregulation of SMAD3 phosphorylation and transcriptional repression of ALK5. Oncol Lett 14: 6031-6039, 2017.

44. Jin Y, Chen W, Yang H, Yan Z, Lai Z, Feng J, Peng J and Lin J: Scutellaria barbata D. Don inhibits migration and invasion of colorectal cancer cells via suppression of PI3K/AKT and TGF- $\beta /$ Smad signaling pathways. Exp Ther Med 14: 5527-5534, 2017.

45. Cai W, Yu D, Fan J, Liang X, Jin H, Liu C, Zhu M, Shen T, Zhang R, Hu W, et al: Quercetin inhibits transforming growth factor $\beta 1$-induced epithelial-mesenchymal transition in human retinal pigment epithelial cells via the Smad pathway. Drug Des Devel Ther 12: 4149-4161, 2018.

46. Fustè NP, Castelblanco E, Felip I, Santacana M, Fernández-Hernández R, Gatius S, Pedraza N, Pallarés J, Cemeli T, Valls J, et al: Characterization of cytoplasmic cyclin D1 as a marker of invasiveness in cancer. Oncotarget 7: 26979-26991, 2016.

47. Georgakilas AG, Martin OA and Bonner WM: p21: A two-faced genome guardian. Trends Mol Med 23: 310-319, 2017.

48. Jung YS, Qian Y and Chen X: Examination of the expanding pathways for the regulation of p21 expression and activity. Cell Signal 22: 1003-1012, 2010.

49. Dai M, Al-Odaini AA, Arakelian A, Rabbani SA, Ali S and Lebrun JJ: A novel function for p21Cip1 and acetyltransferase $\mathrm{p} / \mathrm{CAF}$ as critical transcriptional regulators of TGF $\beta$-mediated breast cancer cell migration and invasion. Breast Cancer Res 14: R127, 2012

50. Dai M, Al-Odaini AA, Fils-Aimé N, Villatoro MA, Guo J, Arakelian A, Rabbani SA, Ali S and Lebrun JJ: Cyclin D1 cooperates with $\mathrm{p} 21$ to regulate TGF $\beta$-mediated breast cancer cell migration and tumor local invasion. Breast Cancer Res 15: R49, 2013.

51. Dasari S and Tchounwou PB: Cisplatin in cancer therapy: Molecular mechanisms of action. Eur J Pharmacol 740: 364-378, 2014.

52. Yin P, Song G and Jiang Z: Cisplatin suppresses proliferation, migration and invasion of nasopharyngeal carcinoma cells in vitro by repressing the Wnt/ $\beta$-catenin/Endothelin- 1 axis via activating $B$ cell translocation gene 1 . Cancer Chemother Pharmacol 81: 863-872, 2018.

53. Luo J, Li YN, Wang F, Zhang WM and Geng $X$ : $\mathrm{S}$-adenosylmethionine inhibits the growth of cancer cells by reversing the hypomethylation status of c-myc and $\mathrm{H}$-ras in human gastric cancer and colon cancer. Int J Biol Sci 6: 784-795, 2010.

54. Lu SC and Mato JM: S-adenosylmethionine in liver health, injury, and cancer. Physiol Rev 92: 1515-1542, 2012.

55. Mahmood N, Cheishvili D, Arakelian A, Tanvir I, Khan HA, Pépin AS, Szyf M and Rabbani SA: Methyl donor S-adenosylmethionine (SAM) supplementation attenuates breast cancer growth, invasion, and metastasis in vivo; therapeutic and chemopreventive applications. Oncotarget 9: 5169-5183, 2018.

This work is licensed under a Creative Commons Attribution-NonCommercial-NoDerivatives 4.0 International (CC BY-NC-ND 4.0) License. 